\title{
Are allografts the biologic valve of choice for aortic valve replacement in nonelderly patients? Comparison of explantation for structural valve deterioration of allograft and pericardial prostheses
}

Nicholas G. Smedira, MD, ${ }^{a}$ Eugene H. Blackstone, MD, ${ }^{a, b}$ Eric E. Roselli, MD, ${ }^{a}$ Colleen C. Laffey, RN, ${ }^{a}$ and Delos M. Cosgrove, $\mathrm{MD}^{\mathrm{a}}$

丹 Supplemental material is available online.
From the Departments of Thoracic and Cardiovascular Surgery a and Quantitative Health Sciences, ${ }^{b}$ The Cleveland Clinic Foundation, Cleveland, Ohio.

Received for publication June 23, 2005; revisions received Sept 6, 2005; accepted for publication Sept 14, 2005.

Address for reprints: Nicholas G. Smedira, MD, The Cleveland Clinic Foundation, 9500 Euclid Ave/Desk F24, Cleveland, OH 44195 (E-mail: smedirn@ccf.org).

J Thorac Cardiovasc Surg 2006;131:558-64 $0022-5223 / \$ 32.00$

Copyright $\odot 2006$ by The American Association for Thoracic Surgery

doi:10.1016/j.jtcvs.2005.09.016
Objective: To compare explantation for structural valve deterioration in nonelderly patients after aortic valve replacement with stented bovine pericardial and cryopreserved allograft valves.

Methods: From 1981 to 1985,478 patients received pericardial prostheses during premarket approval; from 1987 to 2000, 744 patients received cryopreserved allografts. Mean age of patients receiving allografts was $49 \pm 12$ years, and that of those receiving pericardial prostheses was $65 \pm 11$ years; pericardial valves were used in 138 patients younger than age 60 . Mean follow-up was $15 \pm 5.1$ years for pericardial valves (4674 patient-years of follow-up) and $5.6 \pm 3.1$ years for allografts (3892 patient years of follow-up). Multivariable hazard function methodology, age-group stratification, and propensity matching were used to compare age-specific explantation for structural valve deterioration.

Results: Ninety-five pericardial valves and 46 allografts were explanted, and structural valve deterioration was the mechanism of failure in $74 \%$ and $59 \%$, respectively. The risk of structural valve deterioration increased with younger age at implantation for both allografts $(P=.07)$ and pericardial valves $(P<.0001)$, with a similar magnitude of effect in patients age 50 years or younger $(P=.5), 50$ to 60 years $(P=.7)$, and greater than 60 years $(P=.9)$ and in propensity-matched pairs $(P=.2)$. Thus, pericardial valves were as durable as allografts at all adult ages.

Conclusions: Structural valve deterioration is the most frequent cause of valverelated reoperation after both pericardial and allograft aortic valve replacement and is similarly age dependent, suggesting that pericardial valves may be appropriate for nonelderly as well as older persons.

$\mathrm{T}$ The durability of both allografts and stented xenografts used for aortic valve replacement has long been linked to patient age: the younger the patient, the shorter the durability. ${ }^{1-6}$ By conventional guidelines, both porcine xenografts and bovine pericardial stented bioprostheses have been used nearly exclusively in patients older than 65 years, and allografts have been recommended for those with infective endocarditis and for younger patients, for whom lifelong anticoagulation is undesirable. ${ }^{7}$ Increasingly, patients are requesting valve alternatives that do not require anticoagulation.

Allografts have been preferentially chosen for younger patients at this institution because of the perception that they were more durable than stented bioprostheses, despite the increased technical complexity of inserting and removing them. However, extensive experience with, and long-term follow-up of, bovine pericardial aortic bioprostheses, including inserting them in patients younger than 65 years in 


\section{Abbreviations and Acronyms \\ $\mathrm{CL}=$ confidence limit \\ SVD $=$ structural valve deterioration}

premarket testing, has led us to challenge this preference. ${ }^{8}$ Thus, the objectives of the study were to (1) determine the indications for explanting allografts and stented bovine pericardial prostheses used for aortic valve replacement, (2) compare time-related rates of explantation for structural valve deterioration (SVD) as a function of age for these 2 devices, (3) compare reoperative risk, and (4) infer from this information the rationality of using a pericardial bioprosthesis in nonelderly adults.

\section{Patients and Methods \\ Patients}

Pericardial prostheses. Clinical investigation of the CarpentierEdwards stented bovine pericardial bioprosthesis (PERIMOUNT; Edwards Lifesciences LLC, Irvine, Calif) began in 1981. Between September 1981 and January 1984, 267 patients with isolated aortic valve disease (with or without ischemic heart disease) had this prosthesis implanted at 1 of 4 centers as part of the premarketing clinical investigation for the US Food and Drug Administration. Results of its durability to 17 years after implantation have been reported, ${ }^{8}$ and the follow-up used for this study extended to 20 years. To these 267 patients were added 211 who received the prosthesis for non-isolated aortic valve disease during this time frame and through July 1985 at The Cleveland Clinic Foundation. These 478 patients form the pericardial prosthesis arm of the comparison.

Although mean age at implantation was $65 \pm 11$ years (range, 21-86 years), 138 (29\%) were younger than 60 years (Table 1).

Cryopreserved allografts. Between February 2, 1987, and January 1, 2000, 744 patients received a cryopreserved aortic allograft (CryoLife, Inc, Kennesaw, Ga) at The Cleveland Clinic Foundation. These individuals were younger (mean age, $49 \pm 12$ years; range, 18-84) than those receiving pericardial prostheses $(P<.0001)$, with $609(82 \%)$ younger than age 60 . This difference and other differences in patient characteristics and operative details are presented in Table 1. These same characteristics are presented for patients younger than 60 years in Table E1.

Choice of prosthesis. Except for preferential use of allografts for endocarditis, we were unable to determine why one or the other valve was chosen for an individual patient. During the years of this study, it was thought that allografts, inserted as a root, were uniquely free of an age effect on SVD (except in children), with durability likely to extend beyond 25 years. ${ }^{9}$ Similarly, modifications in design and preparation of the pericardial valve were expected to improve durability and make it a reasonable alternative to mechanical prostheses in nonelderly patients. These assumptions led to age heterogeneity, which afforded us the opportunity to compare age-specific explantation for SVD between these 2 types of prosthesis.
TABLE 1. Patient characteristics and operative details

\begin{tabular}{|c|c|c|c|c|c|}
\hline \multirow[b]{2}{*}{ Variable } & \multicolumn{2}{|c|}{$\begin{array}{c}\text { Pericardial* } \\
(n=478) \\
\end{array}$} & \multicolumn{2}{|c|}{$\begin{array}{c}\text { Allograft } t \\
(\mathrm{n}=751) \\
\end{array}$} & \multirow[b]{2}{*}{$P$ value } \\
\hline & No. & $\%$ & No. & $\%$ & \\
\hline Age (y) & & & & & $<.0001$ \\
\hline$<30$ & 5 & 1.0 & 47 & 6.3 & \\
\hline$\geq 30-\leq 40$ & 19 & 4.0 & 154 & 21 & \\
\hline$>40-\leq 50$ & 27 & 5.6 & 205 & 27 & \\
\hline$>50-\leq 60$ & 87 & 18 & 203 & 27 & \\
\hline$>60-\leq 70$ & 185 & 39 & 98 & 13 & \\
\hline$>70$ & 155 & 32 & 37 & 4.9 & \\
\hline Gender & & & & & $<.0001$ \\
\hline Men & 297 & 62 & 555 & 74 & \\
\hline Women & 181 & 38 & 189 & 25 & \\
\hline NYHA class & & & & & $<.0001$ \\
\hline 1 & 52 & 11 & 138 & 18 & \\
\hline II & 239 & 50 & 397 & 53 & \\
\hline III & 138 & 29 & 164 & 22 & \\
\hline IV & 45 & 9.5 & 44 & 5.9 & \\
\hline Unavailable & 4 & & 1 & & \\
\hline Previous cardiac operation & 44 & 9.2 & 232 & 31 & $<.0001$ \\
\hline Endocarditis & 26 & 5.4 & 189 & 25 & $<.0001$ \\
\hline
\end{tabular}

Concomitant procedure

Repair or replacement of another valve

Mitral repair

Mitral replacement

Tricuspid repair

CABG

Thoracic aorta repair

$\begin{array}{rcrcc}20 & 4.2 & 87 & 12 & <.0001 \\ 35 & 7.3 & 9 & 1.2 & <.0001 \\ 2 & 0.4 & 14 & 1.9 & .03 \\ 189 & 40 & 113 & 15 & <.0001 \\ 5 & 1.0 & 0 & 0 & .009\end{array}$

*Stented bovine pericardial prosthesis. $†$ Cryopreserved aortic allograft. $C A B G$, Coronary artery bypass grafting; NYHA, New York Heart Association.

\section{Surgical Technique}

Aortic valve replacement with pericardial prostheses was performed using standard techniques. ${ }^{10}$ Allografts were inserted as a root in 718 patients $(96.5 \%)$ and by the subcoronary technique in $26(3.5 \%) .^{11}$

\section{Follow-up}

Pericardial prostheses. Patient status in the multi-institutional premarket cohort was assessed annually, and the additional Cleveland Clinic cohort was assessed every 2 years, ${ }^{8}$ typically during an office or hospital visit or by means of detailed institutional review board-approved patient questionnaires completed by telephone or mail. Mean follow-up among survivors was $15 \pm 5.1$ years (maximum, 20 years), and 4664 patient-years of data were available for analysis. We considered time-related estimates to be reliable to 19 years.

Cryopreserved allografts. Patients were routinely followed at 2-year intervals by questionnaire, supplemented by cross-sectional follow-up in 2002. Mean follow-up among survivors was $5.6 \pm$ 3.1 years; $10 \%$ of patients were followed more than 10 years, $5 \%$ were followed more than 12 years, and maximum follow-up was 15 years. In total, 3892 patient-years of data were available for 
analysis. We considered time-related estimates to be reliable to 12 years.

End points. The primary end point was valve explantation for SVD determined from echocardiographic, surgical, and pathologic findings. SVD is defined as any change in function of a prosthesis resulting from intrinsic abnormality causing stenosis or regurgitation. ${ }^{12}$ However, SVD is a continuous process that is never continuously monitored (opportunistic echocardiographic estimates of prosthesis status have been reported for the premarket multiinstitutional cohort ${ }^{13}$ ). Therefore, we chose explantation for SVD as a hard end point.

We recognize that the decision for, and timing of, explant depends on many factors. We cannot estimate how many patients had even severe, possibly symptomatic SVD who were not referred for reoperation. Autopsies were performed in an insufficient number of patients to ascertain prosthesis status. The secondary end point was death within 30 days of explantation.

\section{Data Analysis}

Nonparametric estimates of time-related events were obtained using the Kaplan-Meier method. ${ }^{14}$ A parametric method was used to resolve the number of phases of instantaneous risk (hazard function) and to estimate its shaping parameters. ${ }^{15}$ (For additional details, see http://www.clevelandclinic.org/heartcenter/hazard.) Hazard functions were obtained both for the combined group of 1222 patients and for each prosthesis-related group.

A large number of patient variables (and donor variables for patients receiving allografts) were examined, and age at implantation was the only factor found to be associated with SVD (Appendix E1). Therefore, subsequent analysis focused on the influence of age. This included forcing prosthesis type, age, and age-type interactions into parametric models. Bootstrap bagging (1000 replications) was used to suggest the transformation of scale of age required to linearize it with respect to model assumptions. ${ }^{16,17}$

Because of age bias in prosthesis choice, the primary multivariable analysis was supplemented by 3 verification analyses. First, we stratified patients by age groups and compared explantation for SVD within groups. Although the number of patients receiving each prosthesis type was widely discrepant within these age groups, the number of explants on which comparisons primarily depend was similar for each age group for pericardial prostheses. Second, we performed multivariable subgroup analysis parallel to the analysis for patients under age 60. Third, we compared the prevalence of SVD in propensity-matched pairs. For this, we used logistic regression analysis to develop a nonparsimonious model of the propensity to insert allograft valves. ${ }^{18,19}$ From this, a propensity score was calculated for each patient, and this score was used to pairwise match patients.

Depictions of the age effect were made using the specific hazard function and specific age effect for each valve type (nomograms). ${ }^{20}$ Confidence limits (CLs) of parametric estimates are asymmetric but equivalent to $\pm 1 \mathrm{SE}(68 \%)$.

\section{Results}

\section{Valve Explantation}

Ninety-five pericardial valves were explanted, 70 (74\%) for SVD (Table 2). Forty-six allografts were explanted, 27 $(59 \%)$ for SVD.
TABLE 2. Pathophysiology and indication for explantation

\begin{tabular}{|c|c|c|c|c|}
\hline \multirow[b]{2}{*}{ Pathophysiology and indication } & \multicolumn{2}{|c|}{ Pericardial* $^{*}$} & \multicolumn{2}{|c|}{ Allograft $†$} \\
\hline & No. & $\%$ & No. & $\%$ \\
\hline \multicolumn{5}{|l|}{ Pathophysiology } \\
\hline Stenosis & 18 & 27 & 2 & 5.3 \\
\hline Regurgitation & 30 & 45 & 30 & 79 \\
\hline Mixed & 19 & 28 & 6 & 16 \\
\hline Uncertain & 28 & & 8 & \\
\hline \multicolumn{5}{|l|}{ Indication } \\
\hline SVD & 70 & 74 & 27 & 59 \\
\hline Endocarditis & 10 & 11 & 17 & 37 \\
\hline Incidental‡ & 11 & 12 & 0 & 0 \\
\hline Technical & 0 & 0 & 2 & 4.3 \\
\hline Periprosthetic leakage & 1 & 1.1 & 0 & 0 \\
\hline Uncertain & 3 & 3.2 & 0 & 0 \\
\hline Total & 95 & 100 & 46 & 100 \\
\hline
\end{tabular}

$S V D$, Structural valve deterioration. *Stented bovine pericardial prosthesis. $\dagger$ Cryopreserved aortic allograft. $\ddagger$ Generally during subsequent coronary artery bypass grafting or mitral valve replacement.

\section{Explantation for SVD}

At 5, 10, 12, 15, and 19 years, risk-unadjusted freedom from explantation for SVD of pericardial prostheses was $99.5 \%$, $93 \%, 87 \%, 73 \%$, and $47 \%$, respectively, and at 5, 10, and 12 years, these figures were $98.0 \%, 91 \%$, and $77 \%$ for allografts (Figure E1, $A$ ). Instantaneous risk of both pericardial prosthesis and allograft explantation for SVD (hazard function) accelerated exponentially; however, in addition, for allografts there was also a constant hazard due to a small number of early allograft explantations (Figure E1, $B$ ) This constant hazard was largely accounted for by cusp fibrosis in 3 patients, cusp calcification in 3, and noncalcific degeneration in 2, all occurring within 3 years of implantation.

\section{Age and Explantation for SVD}

The apparently higher risk of explantation for SVD among patients receiving allografts compared with pericardial prostheses was related to their younger average age at implantation (Table 3). Within age groups, freedom from explantation for SVD was nearly superimposable (Figures 1, E2, and E3). Although the number of events was small, the risk of SVD was confirmed as being nearly identical in propensitymatched pairs of patients receiving allograft versus pericardial prostheses $(P=.2$; Figure 2$)$.

Within the subgroup of patients under age 60 , there was insufficient power to detect an age-related difference in explantation for SVD among patients receiving allografts, due to both short follow-up and elimination of older patients who experienced few events (see Table 3). However, it was equally true that their age-related deterioration was similar to that of pericardial prostheses for which more information was known (see Table 3). 
TABLE 3. Age and risk of structural valve deterioration

\begin{tabular}{|c|c|c|c|c|}
\hline \multirow[b]{2}{*}{ Risk factor } & \multicolumn{2}{|c|}{ Overall analysis } & \multicolumn{2}{|c|}{ Patients aged $<60 \mathrm{y}$} \\
\hline & Coefficient \pm SD & $P$ value & Coefficient \pm SD & $P$ value \\
\hline \multicolumn{5}{|l|}{ Pericardial prostheses } \\
\hline \multicolumn{5}{|l|}{ Late hazard phase } \\
\hline Younger age ${ }^{*}$ & $-0.59 \pm 0.10$ & $<.0001$ & $-0.48 \pm 0.23$ & .04 \\
\hline \multicolumn{5}{|l|}{ Allografts } \\
\hline \multicolumn{5}{|l|}{ Late hazard phase } \\
\hline Younger age* & $-0.82 \pm 0.46$ & .07 & $-0.55 \pm 0.54$ & .3 \\
\hline \multicolumn{5}{|l|}{ Comparison } \\
\hline \multicolumn{5}{|l|}{ Early hazard phase } \\
\hline Younger age and allografts $†$ & $1.50 \pm 0.61$ & .01 & $1.24 \pm 0.72$ & .09 \\
\hline \multicolumn{5}{|l|}{ Late hazard phase } \\
\hline Pericardial prosthesis & $0.49 \pm 0.48$ & .3 & $0.41 \pm 0.54$ & .4 \\
\hline Younger age* & $-0.70 \pm 0.42$ & $.1 \ddagger$ & $-0.46 \pm 0.48$ & .3 \\
\hline Younger age and pericardial prosthesis* & $0.099 \pm 0.43$ & .8 & $-0.029 \pm 0.52$ & $>.9$ \\
\hline
\end{tabular}

$*(\text { Age } / 50)^{4}$ power transformation. $\dagger(50 /$ Age $)$ inverse transformation. $\ddagger$ When nonsignificant factors (type of prosthesis and its interactions with age) are removed, the significance of age association becomes $P<.0001$ in overall analysis and $P=.04$ in the subgroup of patients under age 60 .

Thus, overall multivariable analysis, stratified actuarial analysis, subgroup analysis, and propensity matching all supported the observation that through at least 12 years, agespecific risk of explantation for SVD was similar for both allografts and pericardial bioprostheses.

\section{Thirty-Day Mortality After Explantation}

Two patients in the allograft group (4.3\%; CL, 1.4\%-10\%) and 4 in the pericardial group (4.2\%; CL 2.1\%-7.5\%) died within 30 days of explantation for any reason. No patient in the allograft group (0\%; CL, 0\%-7.2\%) and 3 of 4 patients in the pericardial group (4.2\%; CL, 1.9\%-8.4\%) died within 30 days of explantation for SVD.

From available data, failing allografts were replaced with another allograft in $16 \%$, a mechanical prosthesis in 52\%, and a biologic prosthesis in $32 \%$. In contrast, only $2 \%$ of explanted pericardial valves were replaced with an allograft at reoperation; mechanical and biologic prostheses were used in $45 \%$ and $53 \%$, respectively.

\section{Discussion}

This study focused on biologic valve durability in nonelderly patients for 2 reasons. First, such patients are increasingly seeking valve alternatives that avoid anticoagulation. Second, we had begun to question our assumptions about allograft durability in such patients. In this comparison, cryopreserved allografts and stented bovine pericardial valves required explantation for SVD at similar age-specific rates.

\section{Allograft and Pericardial Valve Deterioration \\ Explantation for allograft SVD in this series (23\% at 12 years) was similar to results published by O'Brien and colleagues. ${ }^{21}$ In their experience, $39 \%$ of patients between ages 41 and 60 underwent reoperation by 15 years postop-}

eratively, but this rapidly increased to $63 \%$ at 18 years. Lund and colleagues ${ }^{22}$ at the Royal Brompton and Harefield Hospitals have described 3 hazard phases for allograft tissue failure: a low early phase, an accelerating phase between 10 and 20 years after operation, and a period of low and constant risk thereafter. This increasing rate of reoperation between 10 and 20 years postreplacement is the most likely explanation for the variability of published rates of reoperation at 15 years. Our data cannot address risk beyond 20 years.

The Carpentier-Edwards pericardial prosthesis is a secondgeneration stented bovine valve that is low-pressure fixed in glutaraldehyde and treated with the anticalcification agent polysorbate (Tween) 80 . The majority of these valves have been used in older patients, in whom they have been quite durable. For patients age 65 or older, the chance of reoperation is less than $10 \%{ }^{8}$ The excellent hemodynamic profile and ease of inserting the prostheses led to liberalizing their use in younger patients during the premarket phase of their introduction.

\section{Young Age and SVD}

Younger age at implantation is associated with accelerated SVD among all stented xenograft aortic valves, including pericardial valves. ${ }^{8}$ For allografts, published data are less definitive. In O'Brien and colleagues' series, ${ }^{9}$ only patients below age 20 had greater rates of reoperation than older age cohorts. In fact, patients between ages 21 and 40 had an estimated 20-year freedom from reoperation of $77 \%$, although for patients between ages 41 and 60 , that figure was $37 \%$. These somewhat erratic results for isolated age groups emphasize the importance of analyzing the entire spectrum of the relation of age to explantation for SVD, in keeping 

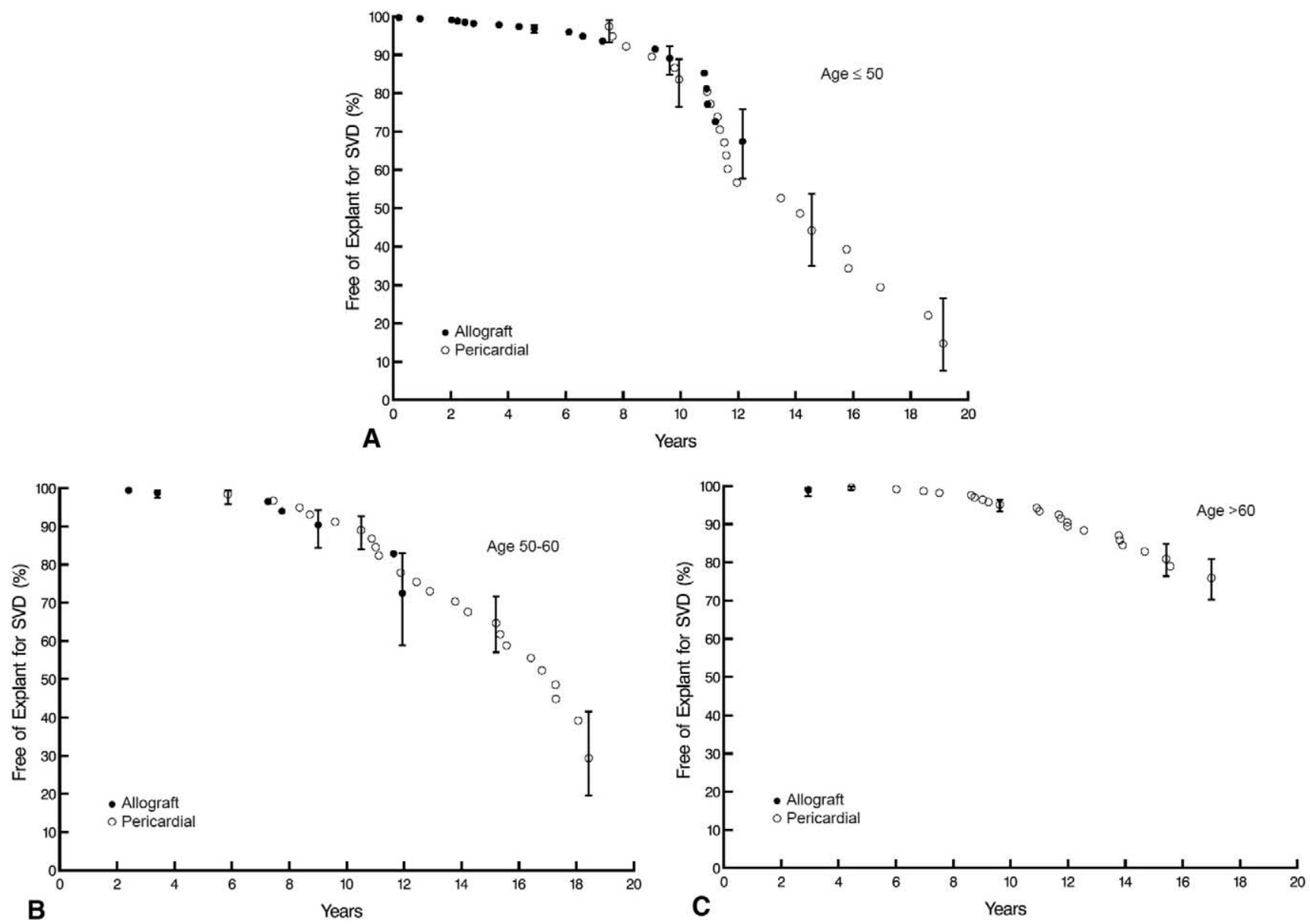

Figure 1. Freedom from explantation for structural valve deterioration (SVD) of stented bovine pericardial bioprostheses (open circles) and allografts (closed circles) used for aortic valve replacement. Vertical bars are asymmetric $68 \%$ confidence limits equivalent to $1 \mathrm{SE}$. A, Patients 50 years of age and younger at valve replacement. There were 406 patients with allografts experiencing 19 events (186 and 32 at risk at 5 and 10 years) and 51 patients with pericardial bioprostheses experiencing 23 events (43 and 29 at risk at 5 and 10 years; $P=.5$ ). B, Patients $>50$ to 60 years of age at valve replacement. Three patients whose indication for pericardial prosthesis explantation could not be determined were excluded. There were 203 patients with allografts experiencing 7 events (103 and 20 at risk at 5 and 10 years) and 84 patients with pericardial bioprostheses experiencing 24 events (67 and 46 at risk at 5 and 10 years; $P=.7$ ). C, Patients 60 years and older at valve replacement. There were 135 patients with allografts experiencing 1 event (70 and 8 at risk at 5 and 10 years) and 340 patients with pericardial bioprostheses experiencing 23 events (254 and 131 at risk at 5 and 10 years; $P=.9$ ).

with the philosophy of "continuity in nature."23,24 In Lund and associates ${ }^{22}$ series, both allograft donor age and patient age were related to SVD. A meta-analysis-microsimulation model predicted only $20 \%$ freedom from allograft SVD at 15 years and demonstrated an age-dependent effect such that patients below age 55 had between a $60 \%$ and $80 \%$ lifetime risk of reoperation for allograft failure. ${ }^{25}$ When the full spectrum of age was considered so that contrasts could become manifest, we, too, found younger age at implantation increased the rate of explantation for SVD for both valves.
Our age-based comparison cannot exclude subtle differences in the 2 cohorts that may have affected the threshold for reoperation, but it is reasonable to believe that most young adults in whom important SVD was detected would be offered reoperation.

\section{Technical Challenges}

Reoperations for allograft failure can be challenging. Allograft wall and valve calcification may be encountered in $50 \%$ of allograft reoperations. ${ }^{26}$ Nevertheless, both allograft and pericardial valve re-replacement can be accom- 


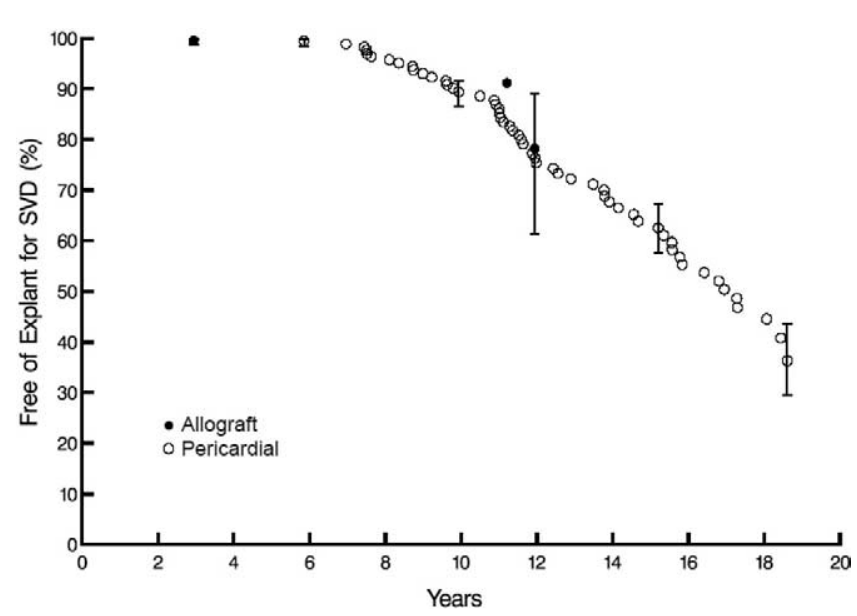

Figure 2. Freedom from explantation for structural valve deterioration of stented bovine pericardial bioprostheses (open circles) and allografts (closed circles) used for aortic valve replacement in propensity-matched patients. Vertical bars are asymmetric $68 \%$ confidence limits equivalent to $1 \mathrm{SE}$.

plished with low mortality. This is crucial if allografts and pericardial valves are to be implanted in nonelderly patients.

\section{Limitations}

SVD is not an event but a time-related process, sporadically monitored, with many factors considered before a bioprosthesis is explanted. We do not know how many patients suffered severe symptoms secondary to a dysfunctional valve and either died or were not considered for explantation. A detailed echocardiographic follow-up of allografts found only $5.4 \%$ of root replacements had more than $2+$ regurgitation and only $1.9 \%$ had moderate to severe aortic stenosis at a mean follow-up of 4.2 years. ${ }^{27}$ Similarly, in echocardiographic follow-up of aortic pericardial prostheses, mean gradients increased only slightly, and regurgitation increased slowly over 10 years. ${ }^{13}$ This suggests that the underestimation of valve dysfunction is small.

One way to investigate the degree of underestimation is to assume that any deterioration in clinical status is secondary to SVD. Indeed, the Society of Thoracic Surgeons/ American Association for Thoracic Surgery definition of SVD includes "any change in function (a decrease of one New York Heart Association functional class or more) ... of an operated valve resulting from intrinsic abnormality of the valve that causes stenosis or regurgitation." ${ }^{12}$ However, many other factors can cause functional class deterioration unrelated to prosthesis deterioration. Previously, we have found no relation between young age, a strong correlate of SVD, and time-related deterioration of New York Heart Association functional status in the peri- cardial prosthesis cohort $(P=.8) .{ }^{13}$ Therefore, we have not used change in New York Heart Association class as a surrogate marker for SVD.

This study has several other limitations. First, for pericardial prostheses, it represents a nonrandomized, multiinstitutional study. However, these patients provide the longest follow-up and age spectrum for this prosthesis and thus the most certainty for time-related estimates of explantation for SVD. Second, at our institution, allografts were used preferentially in young adults and those with endocarditis. In addition, their follow-up is shorter than for pericardial valves, and thus time- and age-related risk of explantation for SVD is not as securely estimated. In contrast, although fewer pericardial prostheses were implanted in young adults, their longer follow-up provided equivalent or better information about deterioration at younger ages than did that for allografts. Third, although there were clear differences between the groups of patients receiving pericardial and allograft prostheses, there was little evidence that factors other than age were associated with SVD. Thus, both age stratification and propensity matching on numerous clinical factors demonstrated age-specific equivalency of explantation for SVD for these 2 groups. Fourth, clinical criteria or thresholds for explantation of a dysfunctional valve were not standardized or defined.

\section{Clinical Inferences}

This study was not motivated by a desire to determine which aortic valve prosthesis is best for patients younger than current guidelines for implanting bioprostheses. Rather, we were motivated by our observation that an increasing number of patients are interested in a valve that does not require anticoagulation and by our questioning whether allograft durability might be less than generally assumed or pericardial prosthesis durability better than assumed. For context, we compared our findings for allografts with those of the prosthesis we most commonly implant, the stented CarpentierEdwards PERIMOUNT valve. Alternatives include the Ross procedure, stentless xenografts, valve repair, and mechanical prostheses. Our results provide estimates of age-related occurrence of SVD following allograft and pericardial aortic valve replacement and the risk of re-replacement, which are equivalent. These results provide information for weighing the risks and benefits of choosing a pericardial prosthesis in patients younger than current age guidelines who wish to avoid anticoagulation.

We thank Colleen Laffey, RN, Tanya Ashinhurst, BS, and Jocelyn Piskach, RN, BSN, for assisting with cross-sectional follow-up; Linda DiPaola, BS, for assembling the data for analysis; and Tess Parry, BS, for editorial assistance. Analysis of patient and donor factors for allograft SVD was performed by Jennifer White, MS. 


\section{References}

1. Blackstone EH, Kirklin JW. Death and other time-related events after valve replacement. Circulation. 1985;72:753-67.

2. Barratt-Boyes BG, Roche AH, Subramanyan R, Pemberton JR, Whitlock RM. Long-term follow-up of patients with the antibiotic-sterilized aortic homograft valve inserted freehand in the aortic position. Circulation. 1987;75:768-77.

3. Grunkemeier GL, Bodnar E. Comparative assessment of bioprosthesis durability in the aortic position. J Heart Valve Dis. 1995;4:49-55.

4. Jamieson WR, Munro AI, Miyagishima RT, Allen P, Burr LH, Tyers GF. Carpentier-Edwards standard porcine bioprosthesis: clinical performance to seventeen years. Ann Thorac Surg. 1995;60:999-1006; discussion 1007.

5. Jamieson WR, Burr LH, Miyagishima RT, Germann E, Anderson WN. Actuarial versus actual freedom from structural valve deterioration with the Carpentier-Edwards porcine bioprostheses. Can J Cardiol. 1999;15: 973-8.

6. Hammermeister K, Sethi GK, Henderson WG, Grover FL, Oprian C, Rahimtoola SH. Outcomes 15 years after valve replacement with a mechanical versus a bioprosthetic valve: final report of the Veterans Affairs randomized trial. J Am Coll Cardiol. 2000;36:1152-8.

7. ACC/AHA guidelines for the management of patients with valvular heart disease. A report of the American College of Cardiology/ American Heart Association. Task Force on Practice Guidelines (Committee on Management of Patients With Valvular Heart Disease). J Am Coll Cardiol. 1998;32:1486-588.

8. Banbury MK, Cosgrove DM III, White JA, Blackstone EH, Frater RW, Okies JE. Age and valve size effect on the long-term durability of the Carpentier-Edwards aortic pericardial bioprosthesis. Ann Thorac Surg. 2001;72:753-7.

9. O'Brien MF, Stafford EG, Gardner MA, Pohlner PG, Tesar PJ, Cochrane AD, et al. Allograft aortic valve replacement: long-term follow-up. Ann Thorac Surg. 1995;60:S65-70.

10. Kouchoukos NT, Blackstone EH, Doty DB, Hanley FL, Karp RB. Cardiac surgery. Philadelphia: Churchill Livingstone; 2003. p. 564-71.

11. Milsom FP, Doty DB. Aortic valve replacement and mitral valve repair with allograft. J Card Surg. 1993;8:350-7.

12. Edmunds LH Jr, Clark RE, Cohn LH, Grunkemeier GL, Miller DC, Weisel RD. Guidelines for reporting morbidity and mortality after cardiac valvular operations. Ad Hoc Liaison Committee for Standardizing Definitions of Prosthetic Heart Valve Morbidity of The American Association for Thoracic Surgery and The Society of Thoracic Surgeons. J Thorac Cardiovasc Surg. 1996;112:708-11.

13. Banbury MK, Cosgrove DM III, Thomas JD, Blackstone EH, Rajeswaran J, Okies JE, et al. Hemodynamic stability during 17 years of the Carpentier-Edwards aortic pericardial bioprosthesis. Ann Thorac Surg. 2002;73:1460-5.

14. Kaplan EL, Meier P. Nonparametric estimation from incomplete observations. J Am Stat Assoc. 1958;53:457-81.

15. Blackstone EH, Naftel DC, Turner ME Jr. The decomposition of time-varying hazard into phases, each incorporating a separate stream of concomitant information. J Am Stat Assoc. 1986;81:615-24.

16. Cox DR, Oakes D. Analysis of survival data. London: Chapman and Hall; 1984.

17. Breiman L. Bagging predictors. Machine Learning. 1996;24:123-40.

18. Rubin DB. Estimating causal effects from large data sets using propensity scores. Ann Intern Med. 1997;127:757-63.

19. Blackstone EH. Comparing apples and oranges. J Thorac Cardiovasc Surg. 2002;123:8-15.

20. Kouchoukos NT, Blackstone EH, Doty DB, Hanley FL, Karp RB. Cardiac surgery. Philadelphia: Churchill Livingstone; 2003. p. 254350.

21. O'Brien MF, Harrocks S, Stafford EG, Gardner MA, Pohlner PG, Tesar PJ, et al. The homograft aortic valve: a 29-year, 99.3\% follow up of 1,022 valve replacements. J Heart Valve Dis. 2001;10:334-44; discussion 5 .

22. Lund O, Chandrasekaran V, Grocott-Mason R, Elwidaa H, Mazhar R, Khaghani A, et al. Primary aortic valve replacement with allografts over twenty-five years: valve-related and procedure-related determinants of outcome. J Thorac Cardiovasc Surg. 1999;117:77-90; discussion 91.

23. Bochner S. Continuity and discontinuity in nature and knowledge. In: Wiener PP, editor. Dictionary of the history of ideas: studies of selected pivotal ideas. Vol 1. New York: Charles Scribner's Sons; 1968. p. 492.

24. Blackstone EH. Black death, smallpox, and continuity in nature: philosophies in generating new knowledge from clinical experiences. Thorac Cardiovasc Surg. 1999;47:279-87.

25. Takkenberg JM, Eijkemans JC, van Herwerden LA, Steyerberg EW, Lane MM, Elkins RC, et al. Prognosis after aortic root replacement with cryopreserved allografts in adults. Ann Thorac Surg. 2003;75: 1482-9.

26. Koolbergen DR, Hazekamp MG, de Heer E, Bruggemans EF, Huysmans HA, Dion RA, et al. The pathology of fresh and cryopreserved homograft heart valves: an analysis of forty explanted homograft valves. J Thorac Cardiovasc Surg. 2002;124:689-97.

27. Palka P, Harrocks S, Lange A, Burstow DJ, O'Brien MF. Primary aortic valve replacement with cryopreserved aortic allograft: an echocardiographic follow-up study of 570 patients. Circulation. 2002;105: 61-6.

\section{JTCVS On-Line Manuscript Submission and Review}

The Journal of Thoracic and Cardiovascular Surgery requires authors and reviewers to submit all new and revised manuscripts and reviews via Editorial Manager. Point your browser to http://jtcvs.editorialmanager.com, log in as author or reviewer (as appropriate), and follow the instructions provided.

To retrieve your username and password, click "Forget your password?" on the Editorial Manager log-in page.

If you have questions or experience problems uploading your manuscript or review, please contact the editorial office:

Telephone: 215-762-1854

E-mail: jtcvs@drexel.edu 


\section{Appendix E1. Variables Analyzed}

\section{For Allografts}

Demography. Gender, age, weight, height, body surface area, body mass index, ethnicity, blood type.

Clinical. New York Heart Association functional class, emergency operation.

Aortic valve disease etiology and pathophysiology. Etiology (rheumatic, degenerative, infectious), pathophysiology (regurgitation, aortic stenosis, mixed lesion), bicuspid valve, anulus diameter.

Cardiac comorbidity. Previous myocardial infarction, number of diseased (50\% or greater diameter stenosis) coronary systems, previous cardiac operation.

Noncardiac comorbidity. Smoking history, pharmacologically treated diabetes, hypertension, peripheral vascular disease, chronic obstructive pulmonary disease, creatinine, blood urea nitrogen.

Concomitant procedures. Coronary artery bypass grafting, mitral valve repair, mitral valve replacement, tricuspid valve repair.
Experience. Date of operation.

Donor variables. Gender, age, anulus diameter, blood type.

Donor-recipient mismatch. Gender difference, age difference, blood type differences, difference in anulus diameter.

\section{For Pericardial Valves}

Demography. Gender, age, weight, height, body surface area, body mass index.

Clinical. New York Heart Association functional class, emergency surgery.

Aortic valve disease etiology and pathophysiology. Etiology (rheumatic, degenerative, infectious), pathophysiology (regurgitation, aortic stenosis, mixed lesion).

Cardiac comorbidity. Previous aortic valve replacement, aortic aneurysm repair.

Concomitant procedures. Coronary artery bypass grafting, mitral valve repair, mitral valve replacement, tricuspid valve repair, ascending aorta repair.

Experience. Date of operation. 
TABLE E1. Patient characteristics and operative details in patients under age 60

\begin{tabular}{|c|c|c|c|c|c|}
\hline \multirow[b]{2}{*}{ Variable } & \multicolumn{2}{|c|}{ Pericardial* $(n=138)$} & \multicolumn{2}{|c|}{ Allograft $\dagger(n=609)$} & \multirow[b]{2}{*}{$P$ value } \\
\hline & No. & $\%$ & No. & $\%$ & \\
\hline Age (y) & & & & & $<.0001$ \\
\hline$<30$ & 5 & 3.6 & 47 & 7.7 & \\
\hline $30-40$ & 19 & 14 & 154 & 25 & \\
\hline $40-50$ & 27 & 20 & 205 & 34 & \\
\hline $50-60$ & 87 & 63 & 203 & 33 & \\
\hline Gender & & & & & $<.3$ \\
\hline Men & 97 & 70 & 455 & 75 & \\
\hline Women & 41 & 30 & 154 & 25 & \\
\hline NYHA class & & & & & $<.02$ \\
\hline I & 17 & 12 & 117 & 19 & \\
\hline II & 71 & 52 & 338 & 56 & \\
\hline III & 40 & 29 & 122 & 20 & \\
\hline IV & 9 & 6.6 & 32 & 5.3 & \\
\hline Unavailable & 1 & & 0 & & \\
\hline Previous cardiac operation & 18 & 13 & 162 & 27 & $<.0008$ \\
\hline Endocarditis & 19 & 14 & 128 & 21 & $<.05$ \\
\hline \multicolumn{6}{|l|}{ Concomitant procedure } \\
\hline \multicolumn{6}{|c|}{ Repair or replacement of another valve } \\
\hline Mitral repair & 10 & 7.2 & 75 & 12 & $<.09$ \\
\hline Mitral replacement & 10 & 7.2 & 4 & 0.7 & $<.0001$ \\
\hline Tricuspid repair & 1 & 0.7 & 13 & 2.1 & .3 \\
\hline CABG & 32 & 23 & 70 & 11 & $<.0003$ \\
\hline Thoracic aorta repair & 2 & 1.4 & 0 & 0 & .03 \\
\hline
\end{tabular}

CABG, Coronary artery bypass grafting; NYHA, New York Heart Association. *Stented bovine pericardial prosthesis. †Cryopreserved aortic allograft. 

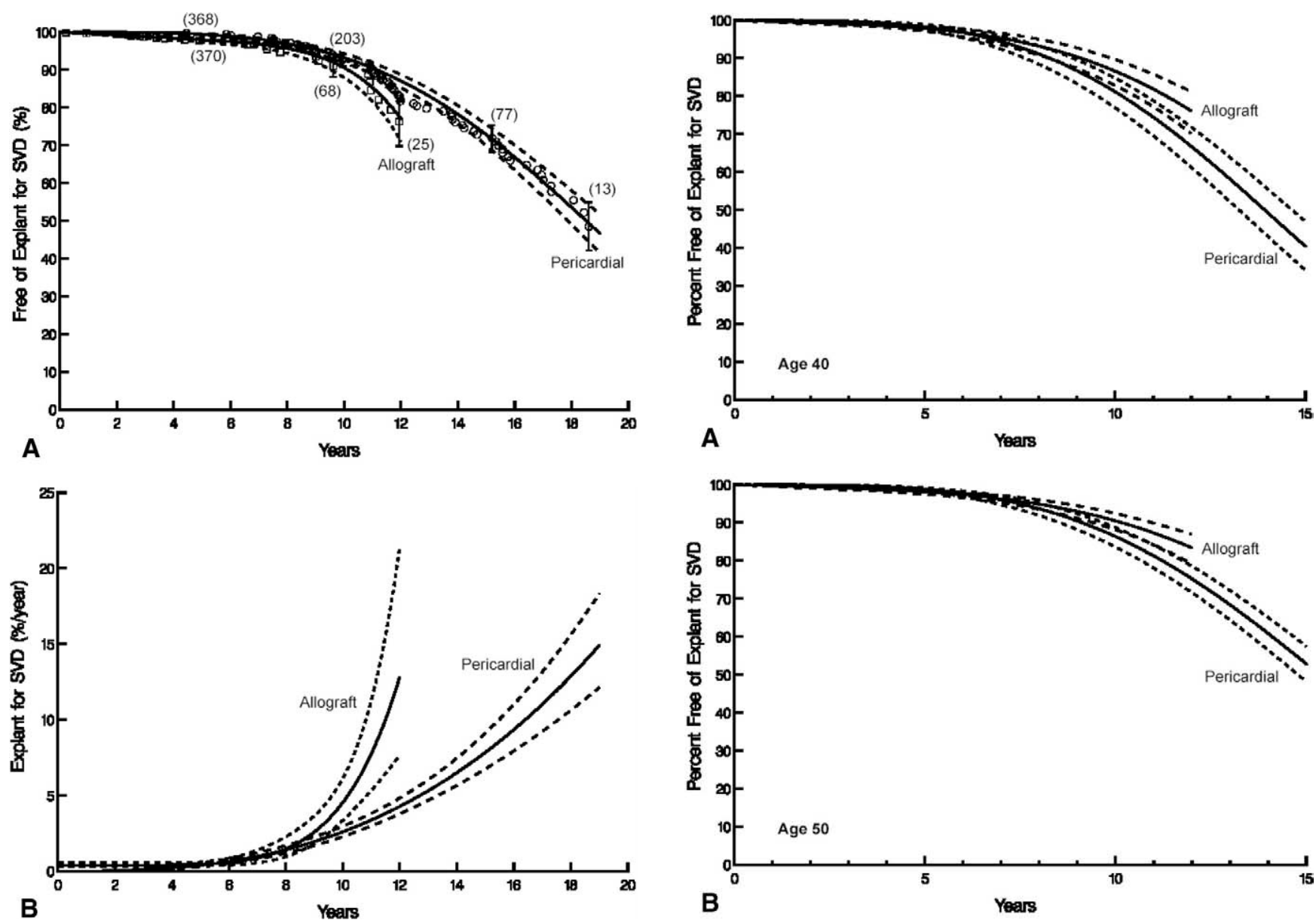

Figure E1. Explantation for structural valve deterioration (SVD) of stented bovine pericardial bioprostheses and allografts used for aortic valve replacement. A, Freedom from explantation for SVD. Symbols represent each event, positioned according to the KaplanMeier method; open circles represent the pericardial group, and open squares, the allograft group. Vertical bars are asymmetric confidence limits equivalent to $1 \mathrm{SE}$. Numbers in parentheses are the number of traced patients. Solid lines are parametric estimates enclosed within dashed confidence limits equivalent to $1 \mathrm{SE}$. B, Instantaneous risk of explantation for SVD (hazard function). The model formed for allografts consisted of a constant hazard phase $(0.35 \%$ per year) and a late rising hazard phase of Weibull shape (hazard $=1.6 \times 10^{-6} t^{4.6}$, where $t=$ time in years since implantation); that for pericardial prostheses consisted of a Weibul late phase (hazard $\left.=1.4 \times 10^{\times 5} t^{3.7}\right)$.

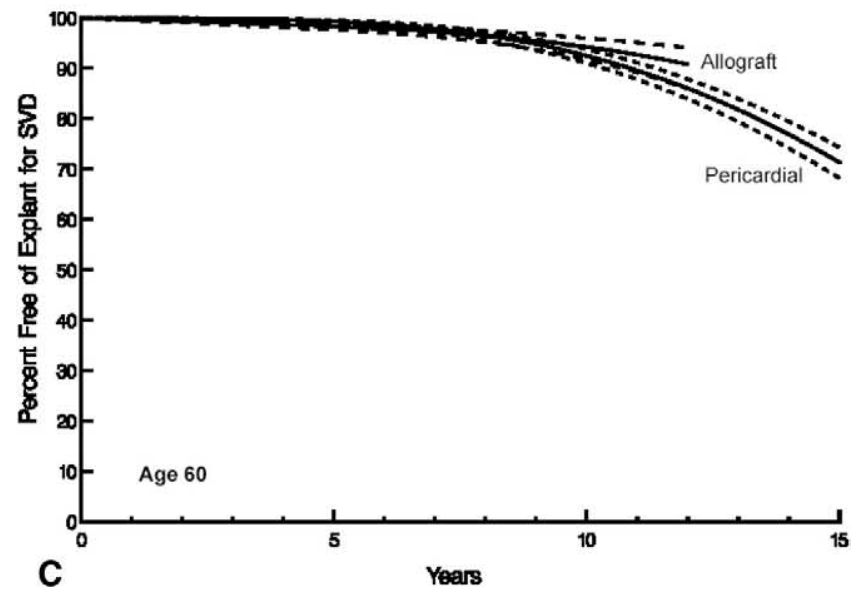

Figure E2. Freedom from explantation for structural valve deterioration (SVD) according to age at implantation. Equations from separate hazard functions for each type of prosthesis (Table 3) were solved for 4 specific ages at index operation. Solid lines are parametric estimates enclosed within dashed confidence limits equivalent to $1 \mathrm{SE}$. A, Age 40 years. B, Age 50 years. C, Age 60 years. 


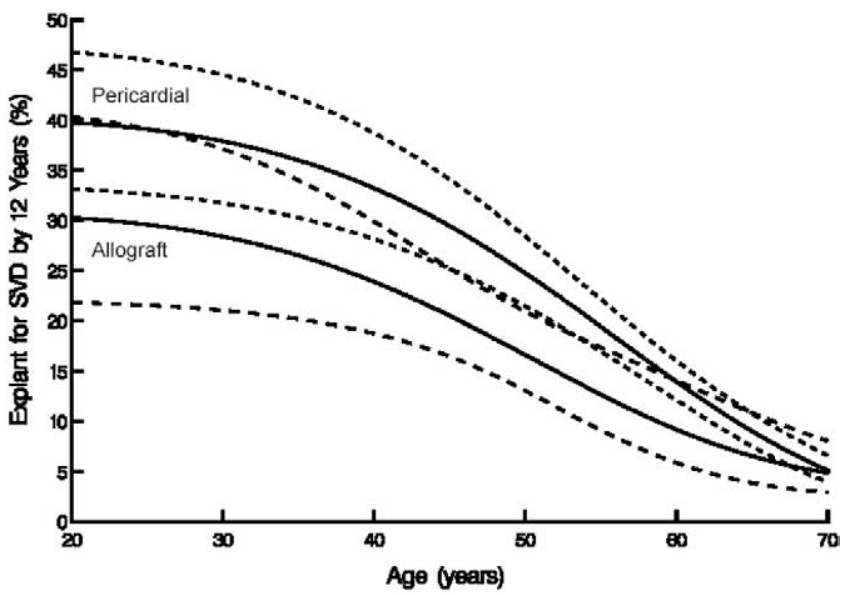

Figure E3. Probability of explantation for structural valve deterioration (SVD) by 12 years as a function of age at implantation. Equations from separate hazard functions for each type of valve (Table 3 ) were solved at 12 years as a continuous function of age at index operation. Solid lines are point estimates. Wide dashed lines are confidence limits for allograft estimates, and fine dashed lines are those for pericardial prostheses. 